\title{
Evidence of donor effect on cultured pearl quality from a duplicated grafting experiment on Pinctada margaritifera using wild donors
}

\author{
Alexandre TAYAlE ${ }^{1,2}$, Yannick Gueguen ${ }^{1}$, Cathy TREguiER ${ }^{1,3}$, Jacqueline Le GRAND ${ }^{1,4}$, \\ Nathalie Cochennec-Laureau ${ }^{1,3}$, Caroline Montagnani ${ }^{1,5}$ and Chin-Long KY ${ }^{1, \mathrm{a}}$ \\ 1 Ifremer, Centre du Pacifique, UMR EIO241, Labex Corail, BP 7004, 98719 Taravao, Tahiti, Polynésie Française \\ 2 University of Neuchatel, Laboratory of Evolutionary Botany, rue Argand 11, 2000 Neuchatel, Switzerland \\ 3 Ifremer, 12 rue des Résistants, BP 86, 56470 La Trinité-sur-mer, France \\ 4 Ifremer, Unité PFOM, UMR 6539 LEMAR, BP 70, 29280 Plouzané, France \\ 5 Ifremer, UMR 5119 CNRS-IRD-Montpellier 2 Univ., 34095 Montpellier, France
}

Received 22 June 2012; Accepted 30 October 2012

\begin{abstract}
Producing high quality cultured black pearls from Pinctada margaritifera is one of the major challenges for the "pearl oyster" industry in French Polynesia. In order to assess donor effect on cultured pearl quality, wild Pinctada margaritifera originating from the Tuamotu Archipelago were used in a duplicated grafting experiment. After 12 months of culture, nucleus retention was assessed and seven pearl quality traits recorded on the 454 cultured pearls harvested from the experiment. The traits scored were nacre thickness and pearl weight, surface defects, lustre, grade, and the colour components: 1) darkness of cultured pearl colour, and 2) visual perception of colour class (bodycolor and/or overtone). Our results demonstrate for the first time that individual wild donors of implanted mantle grafts significantly affect these seven quality traits in P. margaritifera cultured pearls. This finding was repeated in two series of grafts made by different professional grafters. The wild donors could be ranked from "best" (e.g., the donor whose grafts produced the cultured pearl with the maximum lustre) to the "worst". Moreover, we showed strong correlations between: 1) cultured pearl nacre thickness and grade, with grade A showing the greatest nacre thickness on average compared with grade D and rejects; and 2) nacre thickness/cultured pearl weight and colour components (darkness and visual "colour categories"), with the palest cultured pearls (i.e. white cultured pearls) being the smallest (lowest nacre thickness and weight). Thus, one way of enhancing P. margaritifera foundation stocks for a selective breeding program could be to select the "best" donors, using appropriate molecular tools. Generation of selected donor lines from these stocks through hatchery production would be one way to increase the quality of cultured pearl farming of P. margaritifera in French Polynesia.
\end{abstract}

Keywords: Cultured pearl oyster / Pearl quality / Nacre / Donor mollusc / Genetic selection / Pteriidae / Blacklip pearl oyster / Pinctada margaritifera / French Polynesia

\section{Introduction}

In French Polynesia, cultured pearls are produced by the black lipped "pearl oyster", Pinctada margaritifera var. cumingi (Linnaeus 1758), which is mostly distributed in the Tuamotu-Gambier archipelagos. P. margaritifera is widely distributed between the Indo-Pacific tropical and subtropical shallow-water areas, and is mostly associated with reef environments (Cunha et al. 2011). Pearl cultivation has a key position in French Polynesia at economic, environmental and social levels. More than 500 cooperative and private pearl farms operate on 27 atolls, employing thousands of people

\footnotetext{
${ }^{a}$ Corresponding author: Chin.Long.Ky@ifremer.fr
}

(Talvard 2010). The activity contributes not only to the slowdown of human migration from the other islands to Tahiti, but also to the economic development of these areas. Pearl cultivation is the second source of revenue after tourism and is the top export industry. This industry is currently undergoing a crisis, marked by a continuing decline of profits. Both the rapid increase in the number of rearing concessions and the emergence of other producing countries (Australia, China, Indonesia and the Cook Islands) have contributed to increasing the volumes of gems exported, to the detriment of quality. Furthermore, 5 to $10 \%$ of pearls harvested can be qualified as being of top gem quality following the local regulatory control standards; these provide about the $95 \%$ of farms' income (Ellis and Haws 1999). The other 95 to $90 \%$ of the production 
are saleable but not so profitable. In this context an increase in high quality cultured pearls would be a considerable advantage for the industry.

As with any gemstone, prices vary with quality. Five factors are used to define "cultured pearl quality".

1) Size includes the diameter of the sample, which can vary from eight to twenty millimetres, with the largest cultured pearls being the most expensive and nacre thickness of the sample.

2) Shape can be round, near round, button-shaped, oval, pear to drop shape, or completely uneven/asymmetrical ("baroque"), with the perfectly round and symmetrical fetching the highest prices.

3) Colour has two dimensions: bodycolor, which is mainly due to different pigments, and overtone, the secondary (or physical) colour due to diffraction/diffusion of the light on the pearl's surface. The combination of body and secondary colours produces a large spectrum of visually perceived colours, from white to anthracite black through pink, green, blue, cream, aubergine, bronze, or a mix of nearly all these colours that offers a rainbow effect known as peacock.

4) Lustre, or the reflection of light from the edges of the cultured pearl, defines the shininess/glossiness of the surface.

5) Surface quality is an assessment of the (often microscopic) imperfections that can mark a cultured pearl, such as signs of scratches, small holes, unevenness, abrasions, spots and roughness.

On the basis of these five factors, Tahitian cultured pearls are graded, following the official classification using an A, B, C, D nomenclature (see description in Materials and Methods section). In addition, for exportation criteria, all cultured Tahitian pearls must have a minimum thickness of $0.8 \mathrm{~mm}$ between the bead (nucleus) and the external surface of the pearl (Journal Officiel de la Polynésie Française 2005).

Cultured pearls are produced by the interaction of the biological products of two molluscs. The process employs a small piece $(\sim 5 \mathrm{~mm})$ of mantle tissue from a donor oyster (a.k.a., "saibo") which is consequently sacrificed. The tissue piece from this donor is implanted along with a bead nucleus into the gonad of a partly opened host oyster (Cochennec-Laureau et al. 2010). Over time, the tissue from the donor mollusc grows around the bead to produce a pearl sac, which secretes successive nacreous layers onto the bead to produce a cultured pearl (Webster and Anderson 1983; Landman et al. 2001). Both the physiological status and the nacre quality of the inner shell are used as criteria for the selection of donors (Taylor 2002). The donor can strongly influence some cultured pearl quality traits (McGinty et al. 2010; Jerry et al. 2012). Moreover, recent studies have shown that the donor mantle tissue is primarily responsible for the expression of biomineralization genes in the pearl sac (McGinty et al. 2012). Selective breeding of donors could provide a means of improving cultured pearl quality through the propagation of interesting lines in a hatchery system. Such a genetic breeding program would require to broaden our knowledge on donor effect on cultured pearl quality prior to selecting appropriate broodstock. The objective of the present study was to examine the effects of individual wild donors on cultured pearl quality in P. margaritifera. To this end, we designed a standardised and single-site experimental grafting trial composed of a duplicated experiment.

\section{Materials and methods}

\subsection{Experimental animals and grafting procedure}

Pinctada margaritifera var. cumingi pearl oysters were obtained from the wild, i.e. by natural spat collection, and both donors and recipients were reared in the Takaroa lagoon (Tuamotu Archipelago, French Polynesia). At the age of 2 years, these molluscs were transferred to the Rangiroa atoll (Tuamotu Archipelago), where they were reared for 2-3 months prior to grafting. A total of 23 donor individuals were used in a duplicated and simultaneous experimental grafting procedure performed by two professional grafters. One grafter used 12 donor oysters and the other 11 to perform a total of 1380 grafts (60 grafts per donor) over four days. The following nomenclature was used for the two graft experiments: "Rep 1" for the experiment where grafting operations were performed by the grafter who used 12 donor oysters and "Rep 2" for the experiment with the grafter who used 11 donor oysters. The 12 donors in Rep 1 were coded: A1, A2, A3, B2, B3, B4, C2, C3, C4, D1, D2 and D3 (A stands for the first day of grafting, $\mathrm{B}$ for the second, $\mathrm{C}$ for the third and $\mathrm{D}$ for the fourth). The 11 donors in Rep 2 were coded: A6, A7, B7, B8, B9, C7, C8, C9, D6, D7 and D8. No significant differences could be observed between days of graft for any of the measured variables (data not shown).

The donors were selected based on their visible health status (colour of the visceral mass and gills), shell aspect and size, and muscle resistance when opening the shells. Large individuals were selected that could potentially produce a minimum of 60 grafts each. Thirty graft pieces were excised from the mantle edge of each valve of each donor following standard pearl farm procedures. Each receiving mollusc was randomly chosen and grafted by a standard grafting operation using a 2.0 BU nucleus (6.054 mm diameter, $343 \mathrm{mg}$ weight - Nucleus Bio, Hyakusyo Co. Japan). The "receiver" pearl oysters to be grafted were also selected according to their visible health status and were individually labelled (according to donors providing the grafts in experiments Rep 1 and Rep 2). After grafting they were placed in separate net retention bags with mesh size allowing rejected nuclei to be caught. Nucleus rejection (presence of the rejected bead in the bags i.e. outside the molluscs) and receiver mortality were evaluated 42 days after the graft operation. The labelled pearl oysters that retained their grafted nucleus (no bead detected in the bags) were drilled and fixed on long-lines after removing the net retention bags. Cultured pearls were harvested 12 months after grafting.

\subsection{Measurement of cultured pearl quality traits}

Cultured pearls were cleaned by ultrasonication in soapy water (hand washing) with a LEO 801 laboratory cleaner (2 L capacity, $80 \mathrm{~W}, 46 \mathrm{kHz}$ ), they were then rinsed in distilled water. Surface defects, lustre, darkness and colours of the cultured pearls were then evaluated visually by a single operator. 
Two quantitative variables were measured on the cultured pearls: 1) the nacre thickness and 2) the cultured pearl weight, using a digital micrometer and a digital balance, respectively.

Visible sample surface defects including pits, bumps, scratches, deposits or other surface flaws were counted visually (without a magnifier) and each cultured pearl was then classified into one of three categories: no defects, 1 to 5 defects, or more than 5 defects. Circled cultured pearls, characterized by regular streaks or concave rings, were not considered as having surface defects but as being of a particular cultured pearl shape. Shape was not evaluated in this study.

Two kinds of colour evaluation, of the cultured pearls were made: 1) the darkness of colour, with three categories: high, medium and low; and 2) the visually perceived colour category, which is due to pigments (bodycolour) and secondary colour (overtone) and/or a combination of the two, with five "colour categories" detected, into which all the harvested pearls could be classified: white, grey, green, yellow and peacock (a mix of red/ purple and green).

Finally, cultured pearl grade was determined for each sample by a single professional expert according to the official Tahitian classification (http://www.lexpol.pf/ LexpolAfficheTexte.php?texte $=178711$, Journal Officiel 2001 $\mathrm{n}^{\circ} 30,26$ July 2001). Cultured pearl grade was thus attributed, from the most valuable quality to the least: A, B, C, D and "Reject". The four grades are mostly based on surface purity and lustre: (A) cultured pearls showing no surface defects or small defects confined to less than $10 \%$ of their surface and having very good lustre, (B) cultured pearls showing defects distributed over less than one third of their surface and having good or medium lustre, (C) cultured pearls showing defects distributed over less than two thirds (2/3) of their surface and having medium lustre, and (D) cultured pearls showing many very visible defects over more than two thirds $(2 / 3)$ of their surface and having poor lustre. "Rejects" (Rebuts) are cultured pearls that have too many defects to be graded and which are consequently discarded and ultimately destroyed.

\subsection{Statistical analysis}

Differences in nucleus retention rate between wild donors were evaluated using chi-square tests. Kruskall-Wallis tests were used to test for differences in cultured pearl weight among the wild donors at an intra-experiment level (Siegel and Castellan 1988). If the overall test was significant, a Dunn procedure with a Bonferroni correction was performed among all pair of donors (Winer et al. 1991).

Qualitative classes based on cultured pearl surface defects, lustre, grade and darkness were re-encoded to give quantitative scores that would enable the mean value of donors to be obtained for each criterion, thus allowing them to be ranked. Scores from 0 to 4 were attributed to the different classes from the least to the most valuable (with grade, surface defects, darkness and lustre) (Table 1). For each criterion, Kruskall-Wallis tests were then applied to compare donors at an intra-repetition level.

For the cultured pearl "colour categories", cluster analysis was performed at an intra-repetition level based on the proportion of cultured pearls observed in each colour class for each
Table 1. . margaritifera cultured pearl surface defects, lustre, grade and qualitative colour darkness classes were re-encoded into quantitative scores to evaluate the mean value of donor oysters for each criterion, allowing donors to be ranked. Scores from 0 to 4 were attributed to the different classes from the least to the most valuable (with grade, surface defects, darkness and lustre) as shown.

\begin{tabular}{lccccc}
\hline & \multicolumn{5}{c}{ Score } \\
\cline { 2 - 5 } & 0 & 1 & 2 & 3 & 4 \\
\hline Grade & Rebut & D & C & B A \\
Surface defects & $>5$ defects & $1-5$ defect(s) & no defect & - & - \\
Darkness & low & moderate & high & - & - \\
Lustre & without lustre & with lustre & - & - & - \\
\hline
\end{tabular}

donor. Then a $\chi^{2}$-test was applied to test differences between these clusters for experiments Rep 1 and Rep 2 .

To test if there were significant relationships between cultured pearl colour parameters (darkness of coloration or "colour categories") and the thickness of the nacre layer or overall pearl weight, Kruskall-Wallis tests were performed at an intra-experiment level.

In all tests, $p$-values lower than 0.05 were considered significant. All analyses were performed using Xlstat software (version 2009.4.02) (Dagnelie 2007).

\section{Results}

\subsection{Nucleus retention and pearl harvest}

Nucleus retention was evaluated in the duplicate experiments, Rep 1 and Rep 2, after a period of 42 days post-grafting, during which the pearl oysters were not handled (data not shown). The 713 grafted molluscs of the Rep 1 experiment showed an average of $61 \%$ nucleus retention $(N=437)$, with minimum and maximum values of $43 \%$ (25 nuclei retained out of 58 grafts) and $77 \%$ (46 nuclei retained out of 60 grafts), respectively. The 658 grafted molluscs of the Rep 2 experiment showed an average of $64 \%$ nuclei retention $(N=423)$, with a min-max value of $56 \%$ (33 nuclei retained out of 59 grafts) and $78 \%$ (47 nuclei retained out of 60 grafts), respectively. Donor effects were detected for nuclei retention in the Rep 1 experiment ( $p=0.007$ ) but no significant donor effect was detected in the Rep 2 experiment $(p=0.307)$.

After 12 months of culture, 454 cultured pearls were harvested: 257 from Rep 1 and 197 from Rep 2 (Table 2). The quality traits were recorded on these cultured pearls as described in Sect. 2. The number of pearls harvested (in brackets) per donor in Rep 1 was as follows: A1 (13), A2 (28), A3 (30), B2 (9), B3 (26), B4 (27), C2 (24), C3 (28), C4 (23), D1 (27), D2 (12) and D3 (10). The number of pearls harvested (in brackets) per donor in Rep 2 donors was as follows: A6 (13), A7 (17), B7 (5), B8 (21); B9 (14), C7 (32), C8 (25), C9 (14), D6 (20), D7 (21) and D8 (15).

\subsection{Nacre thickness and cultured pearl weight}

Nacre thickness distribution for Rep 1 and Rep 2 experiments is presented (Fig. 1a). Rep 1 showed an average nacre 


\section{a. Nacre thickness}
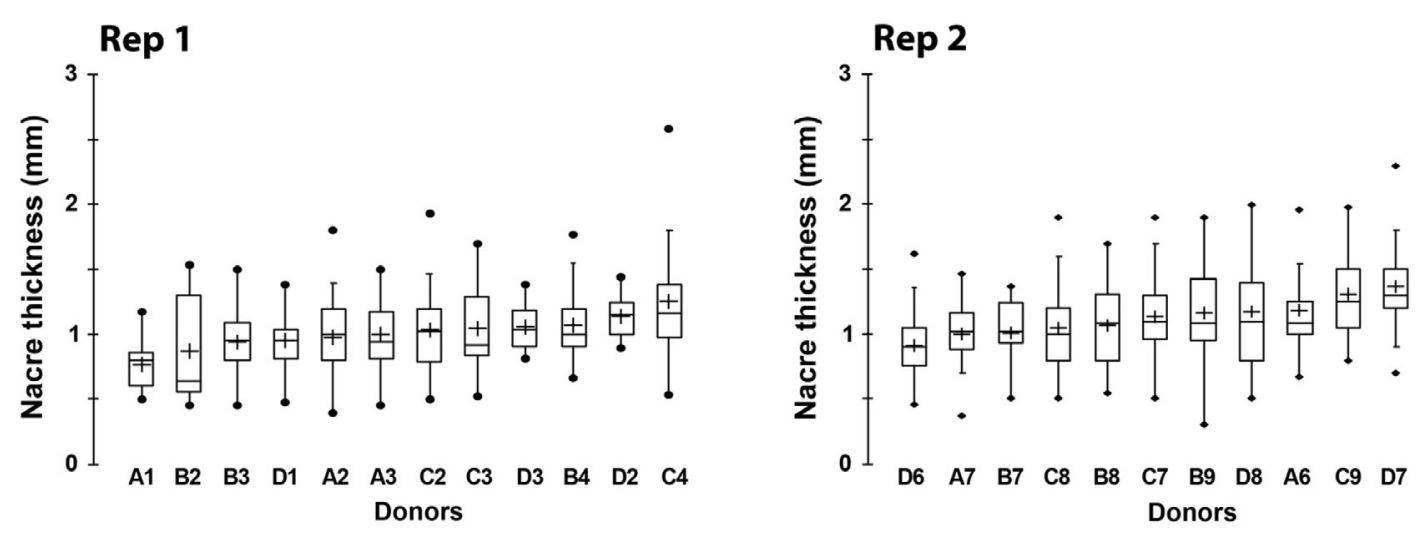

\section{b. Pearl weight}
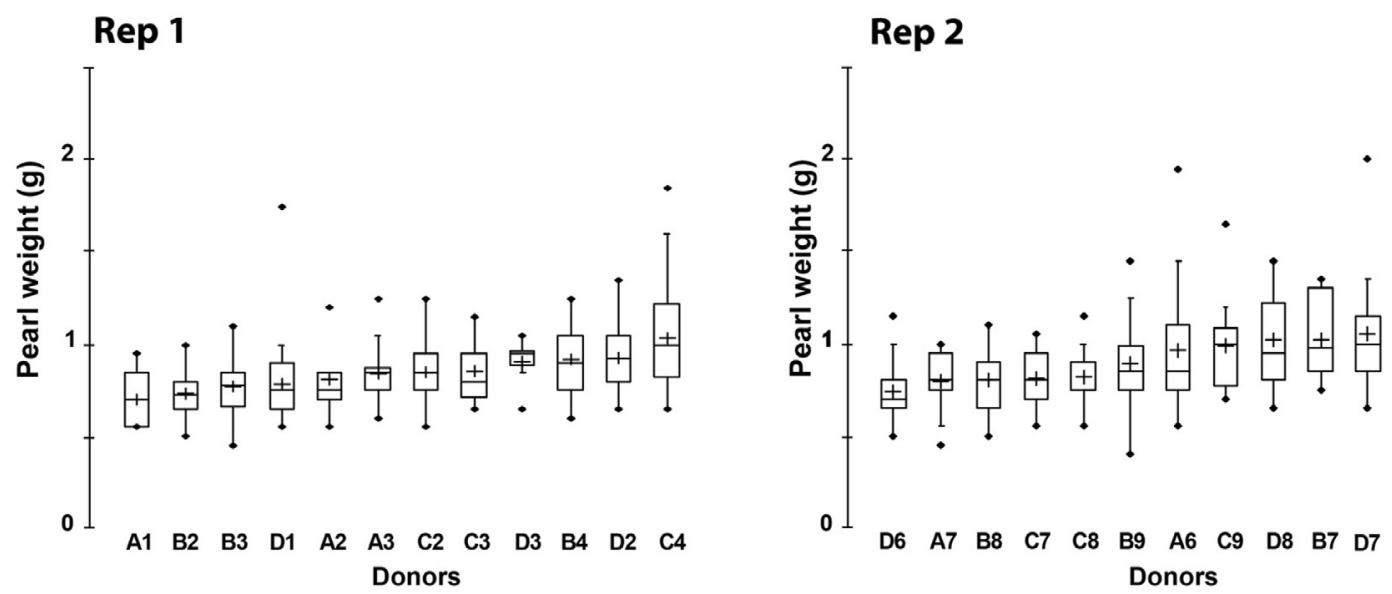

Fig. 1. Box-plot (McGill et al. 1978) showing (a) Nacre thickness (in mm) and (b) Pearl weight (in g) of cultured pearls produced using graft tissue from each of the P. margaritifera donors, in two duplicate grafting experiments (Rep 1 and Rep 2). Donor molluscs are each named with a letter followed by a number. Each box-plot has the following 6 elements: 1) mean ("+" cross in the box-plot); 2) median (solid bar in the box-plot); 3) 25th to 75th percentile (rectangular box); 4) $1.5 *$ interquartile range (non-outlier range of the box whiskers); 5) minimum and maximum values (extreme dots) and 6) outlier values (outside box whiskers). For nacre thickness, within each experimental graft, the donors are ranked according to the nacre thickness from the donor associated with the thinnest nacre in the harvested cultured pearls (A1 and D6) to the donor associated with the thickest nacre (C4 and D7) in Rep 1 and Rep 2, respectively. For pearl weight, the donors are ranked from those associated with the heaviest pearls (A1 and D6) to those associated with the lightest pearls (C4 and D7) in Rep 1and Rep 2 respectively.

Table 2. Summary of the number of $P$. margaritifera wild donors, the number of grafted oysters, the number that retained their nucleus and the number from which pearls were harvested during two duplicate graft experiments (Rep 1 and Rep 2). Number differences between lines: $b-c$ are due to insufficient "saibo" per donor; $c-d$ to post-graft mortality and $d-e$ to mortality and/ or predation (e.g. triggerfish, ray).

\begin{tabular}{lcc}
\hline & Rep 1 & Rep 2 \\
\hline $\begin{array}{l}\text { a. Donor oysters } \\
\text { b. Theoretically grafted oysters }\end{array}$ & 720 & 11 \\
$\quad$ (60 grafts from each donor) & 660 \\
$\begin{array}{l}\text { c. Grafted oysters (graft operation) } \\
\text { d. Oysters that retained their nuclei } \\
\quad \text { (42 days post-graft operation) }\end{array}$ & 713 & 658 \\
$\begin{array}{l}\text { e. Oysters from which a pearl was harvested } \\
\quad(+12 \text { months post-graft operation) }\end{array}$ & 257 & 423 \\
\hline
\end{tabular}

thickness of $1.02 \mathrm{~mm}$, with minimum and maximum values of $0.40 \mathrm{~mm}$ and $2.58 \mathrm{~mm}$, respectively. Donor effects for this trait in Rep 1 were highly significant with $p=0.002$. In this experiment, pearls harvested from donor A1 showed the lowest mean nacre thickness $(0.81 \mathrm{~mm})$ compared with donors D2 $(1.14 \mathrm{~mm})$ or C4 $(1.25 \mathrm{~mm})$, whose resulting cultured pearls had the thickest nacre $(p=0.0008)$. Rep 2 showed an average cultured pearl thickness of $1.12 \mathrm{~mm}$ (with minimum and maximum values of $0.30 \mathrm{~mm}$ and $2.30 \mathrm{~mm}$, respectively. Donor effect for this trait in Rep 2 was highly significant with $p=0.005$. In this experiment, pearls harvested from donor D6 showed the lowest mean nacre thickness $(0.91 \mathrm{~mm})$ compared with donor D7 $(1.36 \mathrm{~mm})$, whose cultured pearls had the thickest nacre $(p=0.0009)$. A significant difference was detected for mean nacre thickness in Rep 1 and Rep 2 experiments $(p=0.001)$. 


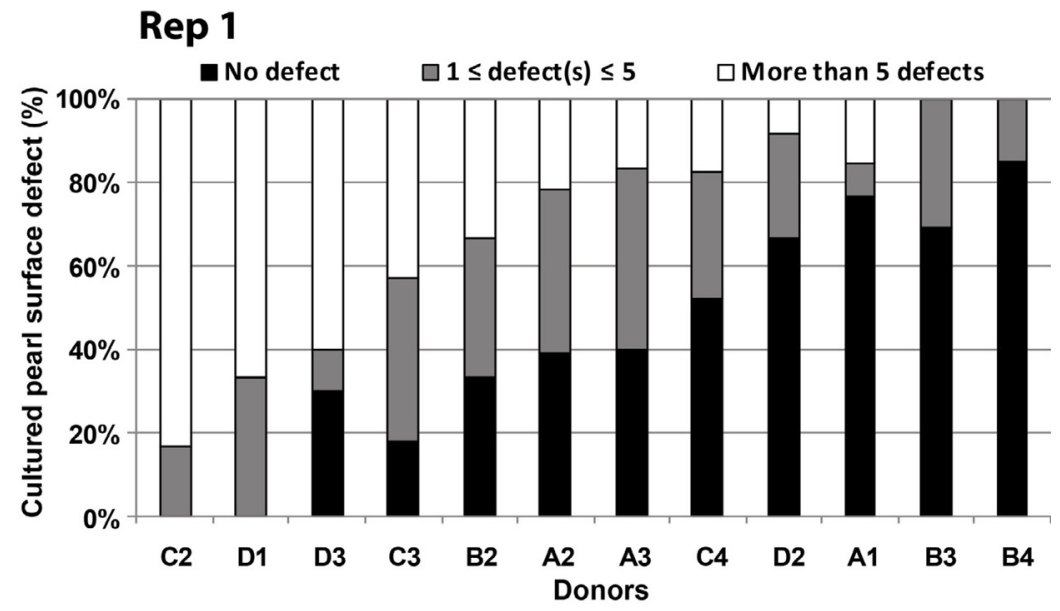

\section{Rep 2}

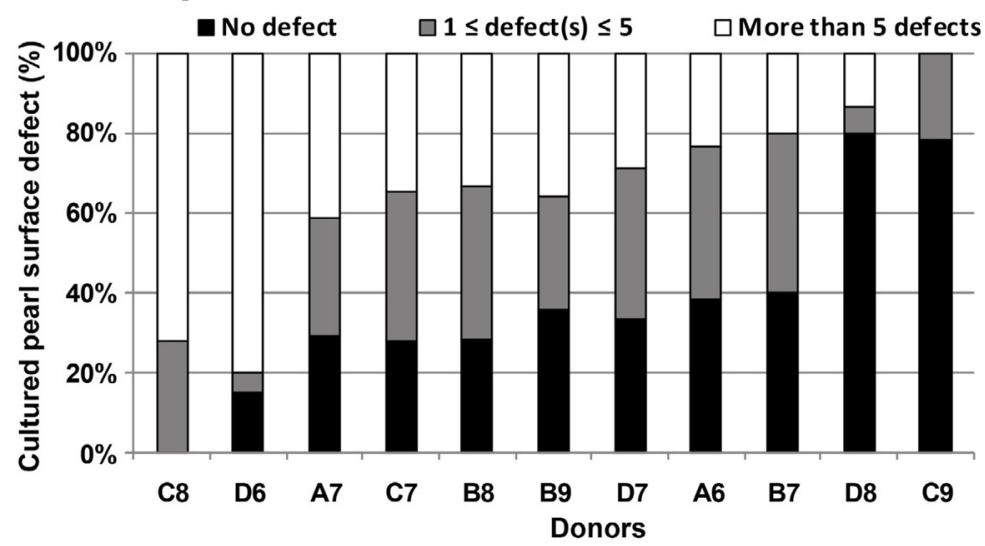

Fig. 2. Proportion of pearl surface defects (in $\%$ for each of the following categories: no defect, 1 to 5 defects, more than 5 defects), in pearls from each of the P. margaritifera donors in two duplicate grafting experiments (Rep 1 and Rep 2). Donor molluscs are named with a letter followed by a number. Within each experimental graft, the donors were ranked from those associated with the pearls that had the most defects (C2 and C8) to those associated with the pearls with the least defects (B4 and C9) in Rep 1 and Rep 2, respectively.

Cultured pearl weight distribution in experiments Rep 1 and Rep 2 (Fig. 1b) showed that Rep 1 had an average cultured pearl weight of $0.85 \mathrm{~g}$ with minimum and maximum values of $0.45 \mathrm{~g}$ and $1.85 \mathrm{~g}$, respectively. Donor effect for this trait in Rep 1 was highly significant, with $p<0.0001$. In this experiment, pearls from donors A1 $(0.71 \mathrm{~g})$ and B2 $(0.72 \mathrm{~g})$ were the lightest on average compared with those from donors C4 (1.04 g), C2 (0.93 g) or C3 (0.92 g) $(p \leqslant 0.0008)$. Rep 2 had an average cultured pearl weight of $0.88 \mathrm{~g}$, with minimum and maximum values of $0.40 \mathrm{~g}$ and $2.00 \mathrm{~g}$, respectively. Donor effect for this trait was also highly significant in Rep2, with $p<0.0002$. In this experiment, cultured pearls produced with donor D6 were on average lighter in weight $(0.74 \mathrm{~g})$ than the cultured pearls from donors D7 (1.05 g), B7 (0.99 g) and D8 $(1.02 \mathrm{~g})(p<0.0009)$

\subsection{Cultured pearl surface defect, lustre and grade}

Incidence of cultured pearl surface defects among donors in experiments Rep 1 and Rep 2 is illustrated (Fig. 2). In the Rep 1 experiment, the 257 harvested pearls were distributed among each of the surface defect classes as follows: $41 \%$
$(N=105)$ with no defect, $29 \%(N=75)$ with 1 to 5 defects and $30 \%(N=77)$ with more than 5 defects. The surfaces of some of the harvested pearls were totally covered in defects (4\%, $N=11)$. In the Rep 2 experiment, the 197 harvested pearls were distributed as follows: $33 \%(N=65)$ with no defect, $28 \%(N=56)$ with 1 to 5 defects and $39 \%(N=76)$ with more than 5 defects. Here also, some cultured pearl surfaces were totally covered in defects $(5 \%, N=10)$. Intra-experiment analysis showed a highly significant donor effect for cultured pearl surface defect percentage $(p<0.0001)$ for both Rep 1 and Rep 2 experiments.

Cultured pearl lustre (matte or shiny/glossy) in experiments Rep 1 and Rep 2 (Fig. 3): showed that 90\% ( $N=$ $257)$ and $94 \%(N=197)$ of the harvested pearls presented a shiny/glossy lustre level, respectively. Donor effects were highly significant in Rep $1(p<0.0005)$ and significant in Rep 2 ( $p=0.022$ ). In Rep 1, pearls harvested from donors A3, D1 and D3 showed significantly better lustre on average compared with donors D2 and B4 $(p<0.0008)$. In Rep 2, pearls harvested from donors A6, A7, B7, C7 and D8 showed a significantly more shiny lustre on average compared with donor B9 $(p=0.0009)$. 

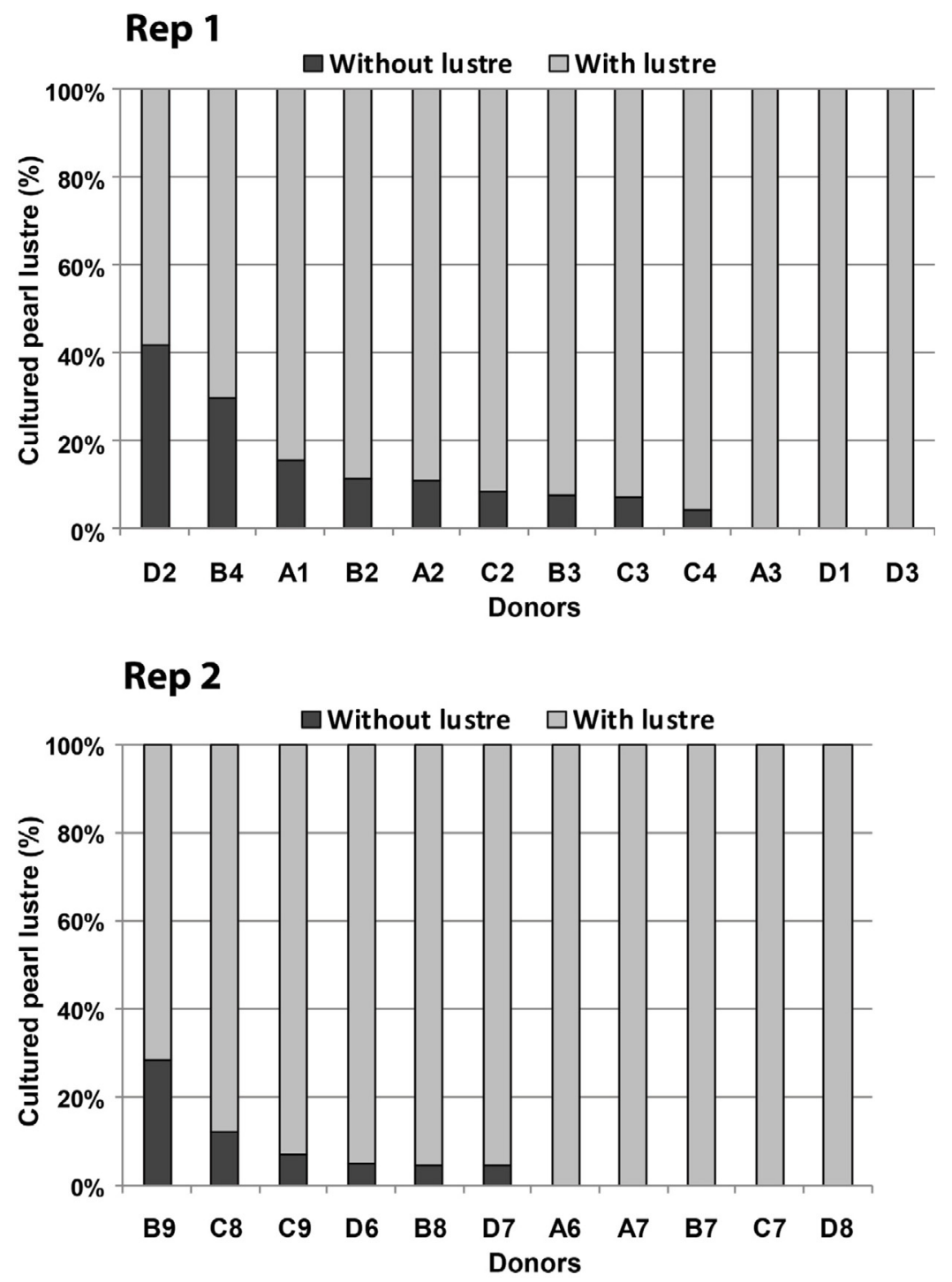

Fig. 3. Cultured pearl lustre distribution (in \% for each of the two following categories: with and without lustre), that come from each of the P. margaritifera donors as part of the two duplicate experimental graft (Rep 1 and Rep 2). Donors are named with a letter followed by a number. Within each experimental graft, the donors are ranked from the donor associated with the least lustrous cultured pearl harvested (D2 and B8) to the donor associated with the most lustrous cultured pearl harvested (D3 and D8) in Rep 1 and Rep 2, respectively.

The distribution of cultured pearls per grade class in experiments Rep 1 and Rep 2 (Fig. 4) showed that in Rep1, the 257 harvested pearls were distributed as follows: $14 \%(N=37)$ of grade $\mathrm{A}, 16 \%(N=40)$ of grade $\mathrm{B}, 38 \%(N=98)$ of grade $\mathrm{C}$, $27 \%(N=68)$ of grade $\mathrm{D}$ and $6 \%(N=14)$ of rejects. In Rep 2, the 197 harvested pearls were distributed as follows: $4 \%$ $(N=8)$ of grade $\mathrm{A}, 13 \%(N=24)$ of grade $\mathrm{B}, 45 \%(N=88)$ of grade $\mathrm{C}, 37 \%(N=72)$ of grade $\mathrm{D}$ and $3 \%(N=5)$ of rejects. Intra-experiment analysis showed very highly significant donor effects for cultured pearl grade with $p<0.0001$ for both experiments. In Rep 1 experiment, pearls produced from donors C3, C4 and B4 showed significantly better grades on average than ones from donors A1, A3, B3, B2, C2 and D1 $(p<0.0008)$. In Rep 2, pearls produced from donors B8, and D8 showed significantly better grades on average than ones from donors D6 and C8 $(p<0.0009)$.

\subsection{Cultured pearl "colour": darkness and visual perception (bodycolor and overtone)}

The darkness of colour in cultured pearls from the different donors in experiments Rep 1 and Rep 2 is illustrated in Figure 5. In Rep 1, the 257 harvested pearls were distributed among each of the darkness levels as follows: $30 \%(N=76)$ with low, $26 \%(N=66)$ with medium and $45 \%(N=115)$ with the high darkness level. In Rep 2 experiment, the 197 harvested pearls were distributed among each of the darkness levels as follows: $23 \%(N=46)$ with low, $42 \%(N=83)$ with medium and $35 \%(N=68)$ with high darkness levels. A significant donor effect was recorded in both experiments: $p<0.0001$ and $p=0.002$ in Rep 1 and Rep 2, respectively.

Among all of the harvested pearls $(N=454)$, five "colour categories" were visually detected. The two main cultured 


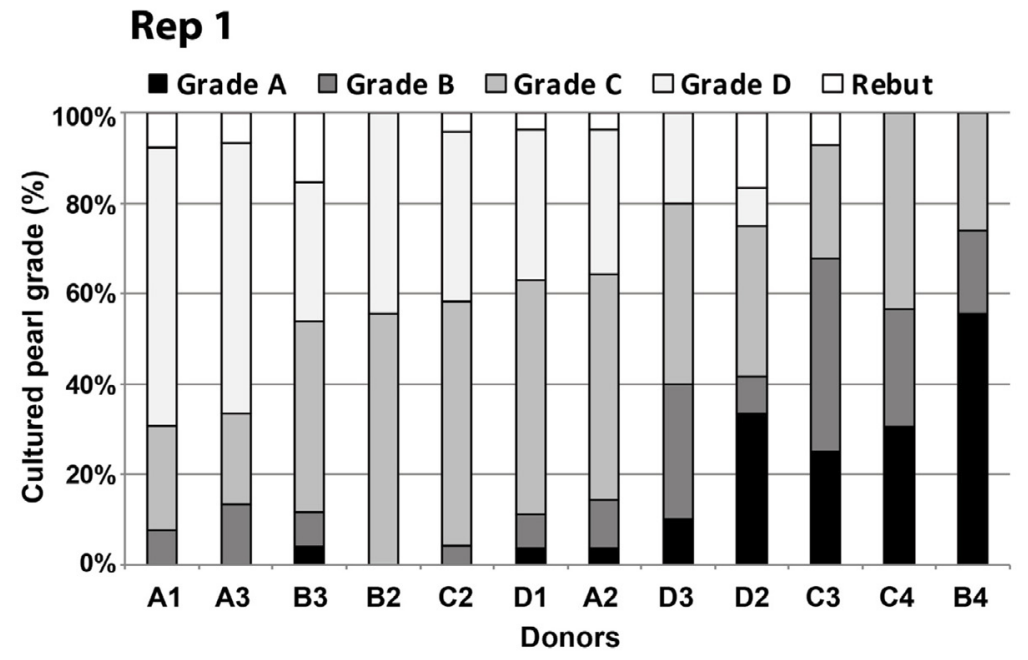

\section{Rep 2}

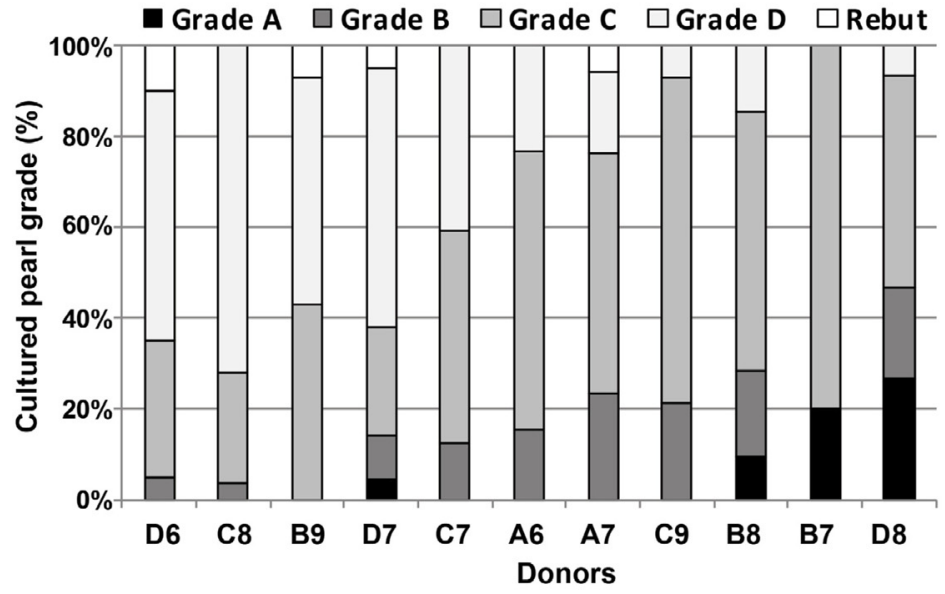

Fig. 4. Cultured pearl classification grade distribution (in \% for the grades: A, B, C, D and Reject according to the Tahitian Classification) for cultured pearls from each of the P. margaritifera donors in two duplicate grafting experiments (Rep 1 and Rep 2). Donors are named with a letter followed by a number. Within each experimental graft, donors were ranked from the one associated with the lowest grade of harvested cultured pearl (A1 and D6) to the one associated with the highest graded cultured pearl harvested (from B4 and D8) in Rep 1 and Rep 2 respectively.

pearl "colour categories" observed were green $(N=170)$ and grey $(N=158)$, and three less frequent "colour categories" were also found: yellow $(N=43)$, white $(N=41)$ and peacock $(N=39)$. In Rep 1 , the proportions of the different colour groups, in decreasing order of frequency, were: $40 \%$ with green shades $(N=103), 33 \%$ with grey shades $(N=84)$, $12 \%$ with white shades $(N=31), 9 \%$ with yellow shades $(N=22)$ and $5.5 \%$ with peacock shades $(N=14)$. In Rep 2, the proportions of the different colour groups, in decreasing order of frequency, were: $38 \%$ grey $(N=74)$, $34 \%$ green $(N=67), 13 \%$ peacock $(N=25), 11 \%$ yellow $(N=21)$ and $5 \%$ white $(N=10)$. Figure 6 shows the different colour proportions produced by each of the donors in Rep 1 and Rep 2, in relationship with the dendrogram profile. Clustering analysis clearly classified the donors in Rep 1 and Rep 2 into groups that were highly significantly different $(p<0.0001)$. In Rep 1, three colour groups could be identified: a peacock group (donors D3 and B4), a white group (donors A1 and A2) and a grey/green group (the other 8 donors). In Rep 2, three colour groups could also be characterized: a green group with low proportion of grey (donors C7, D8 and B7), a yellow group (represented by donor D7) and a grey group (made up of the other 7 donors).

\subsection{Correlations between cultured pearl quality traits}

Among the various cultured pearl quality traits, two major groups of correlations could be identified. The first concerned the cultured nacre thickness, which was correlated with the darkness level, the "colour categories" and the cultured pearl grade. The second concerned the cultured pearl weight which was correlated with the darkness level and the "colour categories".

For cultured pearl nacre thickness in the Rep 1 experiment, highly significant differences $(p<0.0004)$ were recorded between cultured pearl darkness levels (low, medium and high). 

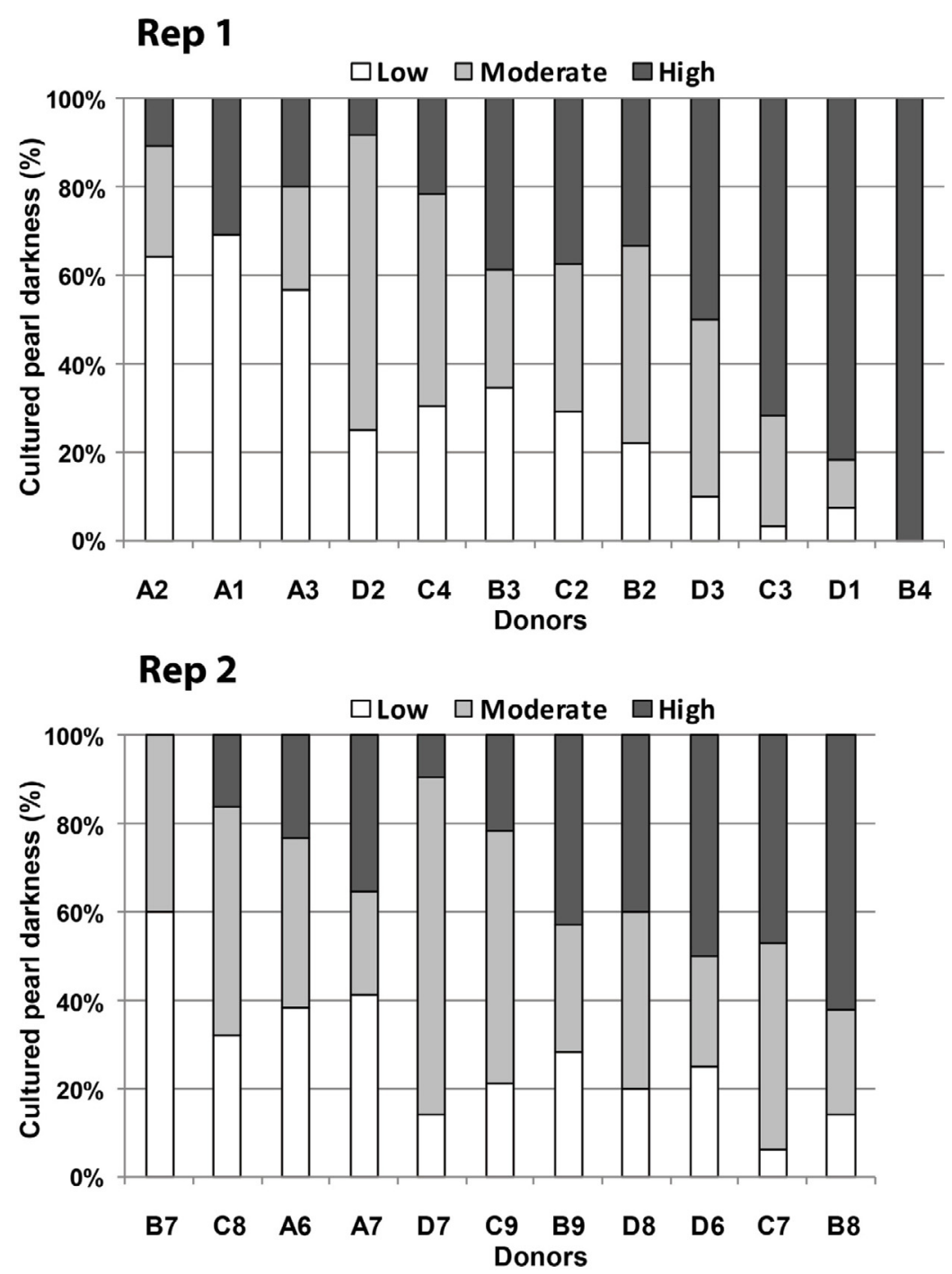

Fig. 5. Colour darkness distribution (in $\%$ for each of the following categories: low, moderate and high darkness) in cultured pearls from each of the P. margaritifera donors in two duplicate grafting experiments (Rep 1 and Rep 2). Donors are named with a letter followed by a number. Within each experimental graft, donors are ranked from the donor associated with the palest cultured pearl harvested (A2 and B7) to the donor associated with the darkest cultured pearl harvested (B4 and B8) in Rep1 and Rep 2, respectively.

For Rep 2, significant differences were also observed $(p=$ 0.026) between these traits. For both experiments, cultured pearls with the lowest darkness level had the lowest average nacre thickness $(0.92 \mathrm{~mm}$ and $1.01 \mathrm{~mm}$ for Rep 1 and Rep 2, respectively) compared with cultured pearls, characterized by both medium and high darkness levels and corresponding to the thickest nacre $(1.08 \mathrm{~mm}$ and $1.05 \mathrm{~mm}$, respectively, for Rep 1 and $1.17 \mathrm{~mm}$ and $1.15 \mathrm{~mm}$, respectively, for Rep 2). A second relationship between cultured pearl "colour categories" (grey, green, peacock, yellow and white) and associated nacre thickness was only seen in Rep 1: mean cultured pearl nacre thickness was very highly significantly different between the "five colour categories" $(p<0.0001)$, with white cultured pearls showing the lowest mean nacre thickness $(0.73 \mathrm{~mm})$ compared with the other "colour categories" $(1.06 \mathrm{~mm}, 1.03 \mathrm{~mm}, 1.07 \mathrm{~mm}$ and $1.18 \mathrm{~mm}$ for green, grey, yellow and peacock cultured pearl, respectively). No significant difference of this kind was detected for Rep $2(p=0.058)$, as the limit of significance was set at $p<0.5$. A third relationship between cultured pearl grade (A, B, C, D and reject) and associated nacre thickness was discovered for only one experiment. For Rep 1, mean cultured pearl nacre thickness was very highly significantly different between the five pearl grades $(p<0.0001)$, with grade A cultured pearls showing the highest nacre thickness $(1.20 \mathrm{~mm})$ compared with grade $\mathrm{D}$ and rebut cultured pearl $(0.81 \mathrm{~mm}$ and $0.90 \mathrm{~mm}$ in average respectively). Again, no significant difference of this sort was detected in experiment Rep 2.

For cultured pearl weight in experiment Rep 1, highly significant differences $(p<0.0001)$ were recorded with cultured pearl darkness levels (low, medium and high). For Rep 2 a significant difference was also observed $(p=0.049)$ between these traits. In Rep 1, the cultured pearls with the lowest mean weight $(0.74 \mathrm{~g})$ corresponded to the palest (lowest darkness score) compared with both medium and high levels $(0.89 \mathrm{~g}$ and $0.90 \mathrm{~g}$, respectively). Another relationship was 

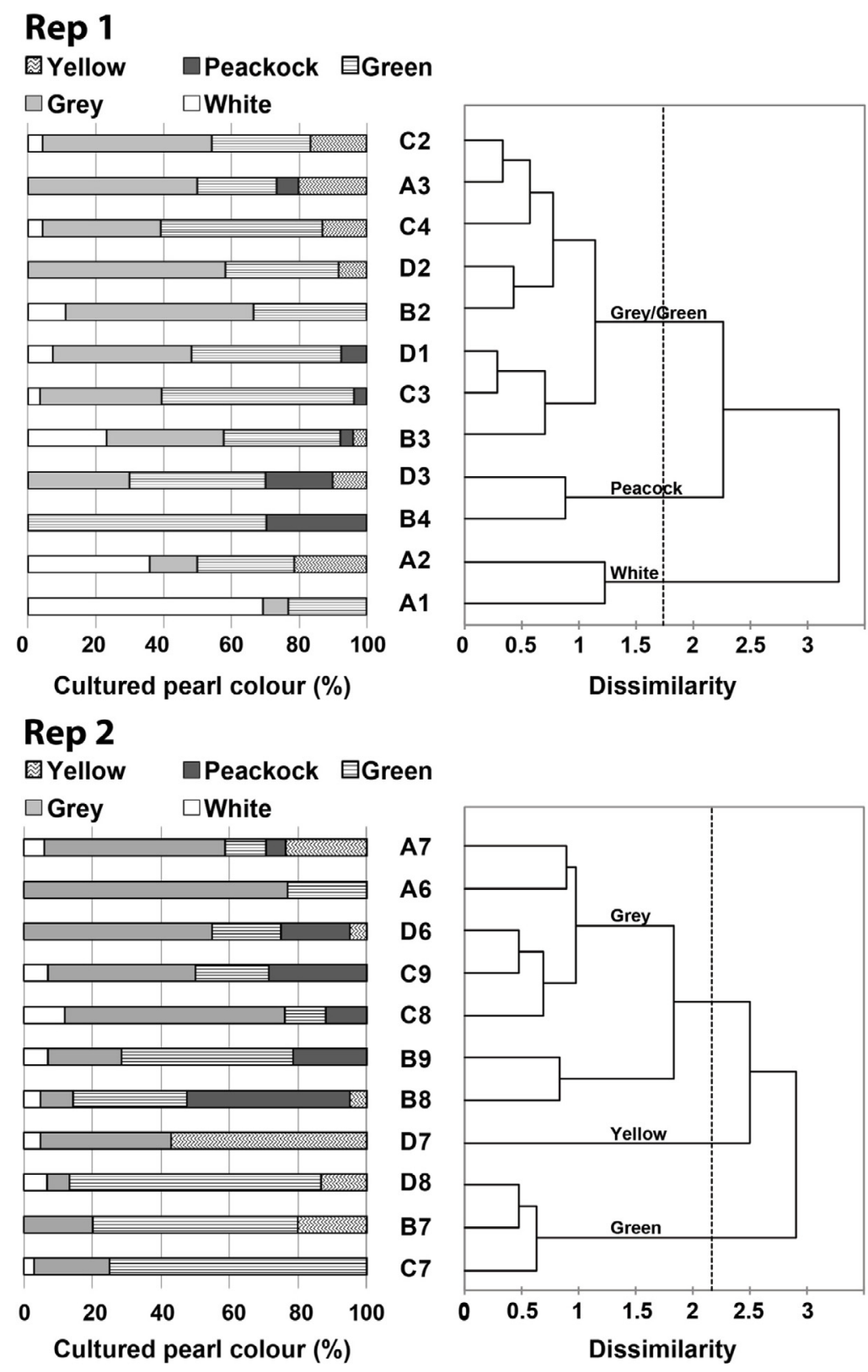

Fig. 6. Distribution of perceived visual colour (bodycolor and overtone) of cultured pearls (in $\%$ for each of the following categories: white, grey, green, yellow and peacock, a mix of red/purple and green), from each of the P. margaritifera donors in two duplicate grafting experiments (Rep 1 and Rep 2). Donors are named with a letter followed by a number. Within each experimental graft, donors were ranked by a cluster analysis, shown by the dendrograms presented next to the histograms. The main branches of the dendrograms classified the cultured pearls harvested associated with each of the donors into three main visually perceived colour groups: grey/green, peacock and white for Rep 1 and grey, yellow and green for Rep 2.

found between cultured pearl "colour categories" (grey, green, peacock, yellow and white) and mean cultured pearl weight was found. For Rep 1, mean cultured pearl weight was very highly significantly different between the five "colour categories" ( $p<0.0001)$, with white cultured pearls having the lowest weights $(0.65 \mathrm{~g})$ compared with the other colours. For Rep 2, mean cultured pearl weight was significantly different between the five "colour categories" ( $p=0.023)$, with white cultured pearls also having the lowest average weight $(0.775 \mathrm{~g})$ compared with the other "colour categories".

\section{Discussion}

In this study, we performed a duplicated grafting experiment (12 wild donor oysters were used to make 713 grafts in the first experiment, and 11 other wild donor oysters were used to make 658 grafts in the second) to evaluate wild donor mollusc effects on cultured pearl quality. Both Rep 1 and Rep 2 experiments showed that cultured pearls produced with the different wild donors were significantly different for all quality traits studied (nacre thickness, weight, surface defect, lustre, 
grade, darkness and "colour categories"). Our data clearly demonstrate that individual wild donors play a significant role in cultured pearl quality traits. A donor effect on nuclei retention was only found in the first experiment, suggesting that this trait is less influenced by individual donors.

\subsection{Nacre thickness and cultured pearl weight}

Nacre thickness and cultured pearl weight differed significantly between wild donors in our two experiments.

The average nacre thickness of the cultured pearls produced from the extreme donor molluscs in both experiments (A1 vs. C4 in Rep 1 and D6 vs. D7 in Rep 2) showed up to $33 \%$ of difference. As the nacre thickness of a cultured pearl is has been seen to depend on the species of pearl oyster, it is clear that this trait has a genetic basis. Some wild donor oysters have the potential to promote more rapid nacreous deposition and/or thicker aragonite tablets than others (and so, deposit higher nacre layers) and therefore represent an interesting characteristic for genetic selection. Such differences in aragonite thickness and/or shell deposit rate have been observed for $P$. maragaritifera grown at different trophic levels (Linard et al. 2011). This ability is driven by the mineralizing properties of the calcifying tissue (mantle for the shell and pearl sac for the cultured pearl), which has been actively studied for P. margaritifera in recent years (Joubert et al. 2010; Marie et al. 2011; Montagnani et al. 2011). Given these results and the importance of cultured nacre thickness (pearl size) for the value of a cultured pearl, further studies should be conducted, such as qPCR-based expression studies of candidate genes implicated in high biomineralisation capabilities.

The average weight of the cultured pearls produced from extreme donor molluscs in both experiments (the same mollusc donors than for the nacre thickness, i.e.: A1 vs. C4 in Rep 1 and D6 vs. D7 in Rep 2) showed a difference of approximately $20 \%$. Cultured pearl weight is mainly dependent on biomineralization processes in the pearl sac (Wada 1972). In the process of pearl production, the grafted mantle tissue proliferates around the nucleus to form a layer of secretory tissue, which then deposits successive sheets of nacre onto the nucleus (Cochennec-Laureau et al. 2010). Although research on factors influencing the weight of cultured pearls is limited, the influence of the donor mollusc on cultured pearl weight has already been suggested (McGinty et al. 2010, 2012). In a xenografting experiment using two Pinctada species, P. maxima and $P$. margaritifera, the authors showed that the cells originating from the donor mollusc actively secreted nacreous shell matrix proteins and likely contributed to the biomineralization process of cultured pearl development, with no expression of the specific nacreous genes from the host mollusc (McGinty et al. 2011, 2012).

\subsection{Surface defects, lustre and grade}

Our results concerning cultured pearl lustre also demonstrated a significant influence of the wild donors. A cultured pearl's surface lustre, which corresponds to the glossiness and the reflectivity of cultured pearls, is a critical factor for saleability. Cultured pearl lustre is known to be influenced by environmental factors such as water temperature (pearl farmers pers. comm.). In French Polynesia, pearl farmers from Gambier archipelago restrict pearl harvest to the cold season, when water temperature is low $\left(22^{\circ} \mathrm{C}\right)$. This practice produces pearls with an overall smooth complexion and good lustre. Cold water conditions slow the metabolism of the mollusc, thus slowing the cultured pearl formation process with low rate of nacre deposition or in reducing the thickness of the tablets. Pearl farmers have been able to alter lustre by changing the environmental conditions of culture (Snow et al. 2004). The phenomenon implicated in lustre expression on the surface of a cultured pearl is mostly observed through the iridescent colour quality that is affected by the thickness of the nacre layers (Rousseau and Rollion-Bard 2012). Additionally, a cultured pearl with a defective surface structure shows no iridescent colour (Liu et al. 1999). This relationship is also shown in shells with a high groove density and smooth groove surface, as these produce a strong iridescent colour.

For surface defects, our results also demonstrated a significant wild donor effect. Some wild donors produced a large proportion of cultured pearls without surface defects. This was the case for B4, D8 and C9 donors, where nearly $80 \%$ of the cultured pearls showed no imperfections. Conversely, C2, C8 and D6 donors produced a majority $(>70 \%)$ of cultured pearls with more than five imperfections. Ideally, a cultured pearl's surface should be smooth, clean and shiny. It should have few, if any, bumps or other surface flaws. Once again, in this respect, B4 and D8 were found to be the best donors. Mantle tissue derived from the donor mollusc is, therefore determinant for cultured pearl surface and grade quality traits. Little is known about this relationship but, in $P$. maxima donor mantle tissue, the pearl produced was seen to have a smoother surface complexation (i.e. a higher grade) than that in P. margaritifera donor tissue, regardless of the receiving mollusc species (McGinty et al. 2010), underlining the role played by the donor oyster in this trait.

According to the official Tahitian classification, cultured pearl grade is a combination of lustre and surface defects determined by a professional evaluator. It is therefore not surprising that we recorded the same significant differences for pearl grade as we had had for both cultured pearl lustre and surface defects separately. By splitting cultured pearl grade into its two components, we were able to demonstrate that donor effect also exists when lustre and surface defect traits are considered independently and that they could thus be used as selection traits. From a genetic point of view, this breakdown is necessary as some cultured pearls showing good lustre can exhibit a lot of surface defects, and, inversely, some cultured pearls showing bad lustre can have a perfect surface. The absence of correlation between these two traits suggests that they are not genetically linked or co-selected. Another interesting point is that a very highly significant correlation was found between cultured pearl nacre thickness and grade, with grade A showing the highest nacre thickness in experiment Rep 1. Selection of wild mollusc donors with high potential for nacre deposition could augment the proportion of grade A cultured pearls produced. 


\subsection{Cultured pearl colour: darkness and visual "colour categories"}

Our results clearly demonstrate a highly significant influence of wild donors on both cultured pearl colour darkness and "colour categories".

For cultured pearl darkness, donors A1, A2, A3 and B7 produced a large proportion of pale cultured pearls (up to $50 \%$ ), while this characteristic were much less common in cultured pearls from other donors. Donors C3, D1, B4, D6, B8 and to a lesser extent donor $\mathrm{C} 7$ produced up to $50 \%$ of cultured pearls with a very dark tone, a proportion substantially higher than in the other donors. These differences of colour darkness among wild donors may reflect differences in production of a black colouring agent (Elen 2002), where both melanin and metalloporphyrins have been implicated (Landman et al. 2001). These differences of darkness among donors could also be linked to differences in the nacre nano-structure (Snow et al. 2004). In cultured pearls with thin nacre $(<0.80 \mathrm{~mm})$, presence of thick organic matter can darken the body tone. Indeed, the so-called "blue cultured pearls", which correspond to cultured pearls of a lead-grey colour, are of this nature (Webster and Anderson 1983).

As regards visual colour perception, some wild donors produced unique colour distributions. For example, donor B8 produced a very high proportion of cultured pearls with an attractive peacock category (nearly 50\%), while this "colour category" was rare in other donors. Likewise, in donors D7 and A1, up to $50 \%$ of the cultured pearls were in the yellow and white "colour categories", respectively. The other donors exhibited much larger proportions of the green or grey categories, with less white, yellow or peacock. The extreme cases were donors $\mathrm{C} 7$ and A6, which produced a majority of green and grey cultured pearls, respectively, both being close to $80 \%$ in proportion. Visual colour perception is a combination of two components: 1) bodycolor, which is a result of pigment deposition, and 2) overtone, which consists of the physical/secondary colours. This latter component is thought to depend on the thickness of the coating material and the refractive index of both the coating material and its environment (Pfaff and Reynders 1999). Interference within the gap of organic matrix between the mineral tiles has also been modelled to explain cultured pearl secondary colour (Nagata et al. 1997).

In summary, the variations in darkness and "colour categories" among wild P. margaritifera donors may reflect differences in pigment production, as pigments play a major role (Elen 2002; Karampelas et al. 2011), but could also be linked to differences in the structure of the nacre (Snow et al. 2004). The use of reciprocal xenografts involving two Pinctada species, which produce distinctively different basecoloured pearls ( $P$. maxima, the silver-lip pearl oyster and $P$. margaritifera, the black-lip pearl oyster) showed that the donor is the primary determinant of cultured pearl colour (McGinty et al. 2010). There is also substantial evidence that the cultured pearl nacre colour is related to the biomineralization capacities of the mantle cells used to supply the graft implant and is correlated with the inner shell colour of the donor mollusc. This is in accordance with our observations, particularly on donor D7, which produced large proportion of yellow cultured pearls. Indeed, the inner shell side of D7 was of a yellow colour.
Although research on colour determination in cultured pearls is limited, studies on shell colour genetic factors have been reported in a number of bivalves, such as Mytilus edulis, Argopectens irradians and Fulvia mutica (Innes and Haley 1977; Adamkewicz and Castagna 1988; Fujiwara 1995), and gastropods including Urosalpinx cinerea and Biomphalaria glabrata (Cole 1975; Richards 1985), where simple patterns of colour inheritance were found. Our results therefore suggest that it should be possible to produce lines of donor molluses that can influence cultured pearl colour by selecting molluscs with interestingly coloured inner shells as broodstock; as is already done for pearl cultivation in $P$. maxima. Further research is underway to determine the influence of environmental parameters on cultured pearl darkness and "colour categories"; these parameters were minimized in our present two experiments in order to detect wild donor effects. For each of the two experiments, all grafted "pearl oysters" were cultured at the same location, and the receiving "pearl oysters" were all from a single spat collection.

\section{Conclusion}

By using a duplicated grafting experiment, with a total of 1440 grafts in $P$. margaritifera, and rearing the grafted oysters in conditions designed to minimised environmental, we demonstrated that the donor is a primary determinant for the seven cultured pearl quality traits studied (nacre thickness, cultured pearl weight, surface defect, lustre, grade, darkness and "colour categories"). The persistence of the donor mollusc cells and their activity in the pearl sac supports the observations of professional grafters that cultured pearl quality traits are influenced by the donor mollusc genotype and phenotype (Arnaud-Haond et al. 2007). Our results also show that: 1) nacre thickness is correlated with colour darkness, colour category and, to a lesser extent, grade: the thicker the nacre, the darker the pearl and the higher the proportion of grade A pearls; and 2) cultured pearl weight is correlated with darkness and colour categories, with the largest cultured pearl having the darkest coloration level. Higher nacre deposition potential and so bigger cultured pearl nacre thickness and size may be linked to colour darkness (mostly dark grey and dark green "colour categories").

Improvement of cultured pearl quality by a genetic selection program could be undertaken by selecting interesting wild donors to be used as broodstocks. The use of a multi-trait selection program, taking into account quantitative genetic control and an improved understanding of genetic correlations necessary to avoid inadvertent selection against nontarget traits, may be an effective strategy to improve cultured pearl quality and value. Extrinsic factors must also be studied in a dedicated experimental design to estimate the contribution of environmental variation (water conditions, temperature, trophic level, sanitary status, etc.) and human impact components (cultural practice, grafter effect, etc.) on cultured pearl quality. The complex relationship among cultured pearl quality traits and the genetic/environment interaction has also been shown for P. maxima (Jerry et al. 2012). Such experimental genetic research is currently being conducted by Ifremer in 
partnership with pearl farmers and the Polynesian marine resources office as part of a genetic research program using mass and family selection, where the first generation of $P$. margaritifera pearl oysters are currently being tested in large scale grafting experiment.

Acknowledgements. This study is part of a collaborative project (GDR ADEQUA) supported by the "Service de la Perliculture" of French Polynesia. It was also supported by Ifremer. Authors are grateful to Cedrik Lo, Marie-Estelle Soupé, Corinne Béliard, Bélinda Hui, Florentine Riquet, Peva Levy, Caroline Joubert, Jean-Claude Cochard and the staff of CMNP at Rangiroa for helpful discussions and assistance.

\section{References}

Adamkewicz L., Castagna M., 1988, Genetics of shell colour and pattern in the bay scallop Argopecten irradians. J. Hered. 79, 14-17.

Arnaud-Haond S., Goyard E., Vonau V., Herbault C., Prou J., Saulnier D., 2007, Pearl formation: persistence of the graft during the entire process of biomineralization. Mar. Biotechnol. 9, 113-116.

Cochennec-Laureau N., Montagnani C., Saulnier D., Fougerouse A., Levy P., Lo C., 2010, A histological examination of grafting success in pearl oyster Pinctada margaritifera in French Polynesia. Aquat. Living Resour. 23, 131-140.

Cole T.J., 1975, Inheritance of juvenile shell colour of the oyster drill, Urosalpinx cinerea. Nature 257, 794-795.

Cunha R.L., Blanc F., Bonhomme F., Arnaud-Haond S., 2011, Evolutionary patterns in pearl oysters of the genus Pinctada (Bivalvia: Pteriidae). Mar. Biotechnol. 13, 181-192.

Dagnelie P., 2007, Statistique théorique et appliquée, 3rd edn. De Boeck, Bruxelles.

Elen S., 2002, Spectral reflectance and fluorescence characteristics of natural-valor and heat-treated "golden" south seas cultured pearls. Gems Gemmol. 37, 114-123.

Ellis S., Haws M., 1999, Producing pearls using the black-lip pearl oyster (Pinctada margaritifera). Aquafarmer Inf. Sheet 141, pp. 8.

Fujiwara M., 1995, Inheritance of yellow colouration of the shell in the cockle Fulvia mutica. Nippon Suisan Gakkaishi 61, 927-928.

Innes D.J., Haley L.E., 1977, Inheritance of a shell colour polymorphism in the mussel. J. Hered. 68, 203-204.

Jerry D.R., Kvingedal R., Lind C.E., Evans B.S., Taylor J.U.U., Safari A.E., 2012, Donor-oyster derived heritability estimates and the effect of genotype $\mathrm{x}$ environment interaction on the production of pearl quality traits in the silver-lip pearl oyster, Pinctada maxima. Aquaculture 338, 66-71.

Joubert C., Piquemal D., Marie B., Manchon L., Pierrat F., ZanellaCléon I., Cochennec-Laureau N, Gueguen Y., Montagnani C., 2010, Transcriptome and proteome analysis of Pinctada margaritifera calcifying mantle and shell: focus on biomineralization. BMC Genom. 11, 1-13.

Journal Officiel de la Polynésie française, délibération n²005-42 APF du 4 février 2005.

Karampelas S., Fritsch E., Gauthier J.-P., Hainschwang T., 2011, UVVis-NIR reflectance spectroscopy of natural-colour saltwater cultured pearls from Pinctada margaritifera. Gems Gemmol. 47, $31-37$.
Landman N.H., Mikkelsen P.M., Bieler R., Bronson B., 2001, Pearls, a natural history. American Museum of Natural History \& Harry N. Abrams Inc., New York, pp. 32-54.

Liu Y., Shigley J.E., Hurwit K.N., 1999, Iridescence color of a shell of the mollusk Pinctada margartifera caused by diffraction. Optics Express 4, 177-182.

Linard C., Gueguen Y., Moriceau J., Soyez C., Hui B., Raoux A., Cuif J.P., Cochard J.C., Le Pennec M., Le Moullac G., 2011, Calcein staining of calcified structures in pearl oyster Pinctada margaritifera and the effect of food resource level on shell growth. Aquaculture 313, 149-155.

Marie B., Joubert C., Belliard C., Tayale A., Zanella-Cléon I., Marin F., Gueguen Y., Montagnani C., 2011, Characterization of MRNP34, a novel methionine-rich nacre protein from the pearl oysters. Amino Acids 42, 2009-2017.

McGinty E.L., Evans B.S., Taylor J.U.U., Jerry D.R., 2010, Xenografts and pearl production in two pearl oyster species, $P$. maxima and P. margaritifera: effect on pearl quality and a key to understanding genetic contribution. Aquaculture 302, 175-181.

McGinty E.L., Zenger K.R., Taylor J.U.U., Evans B.S., Jerry D.R., 2011, Diagnostic genetic marker unravel the interplay between host and donor oyster contribution in cultured pearl formation. Aquaculture 304, 20-24.

McGinty E.L., Zenger K.R., Jones D.B., Jerry D.R., 2012, Transcriptome analysis of biomineralisation-related genes within the pearl sac: host and donor oyster contribution. Mar. Genom. 5, 27-33.

McGill R., Tukey J.W., Larsen W.A., 1978, Variations of box plots. Am. Stat. 32, 12-16.

Montagnani C., Marie B., Marin F., Belliard C., Riquet F., Tayalé A., Zanella-Cléon I., Fleury E., Gueguen Y., Piquemal D., Cochennec-Laureau N., 2011, Pmarg-pearlin is a matrix protein involved in nacre framework formation in the pearl oyster Pinctada margaritifera. Chembiochem 12, 2033-2043.

Nagata N., Dobashi T., Manabe Y., Usami T., and Inokuchi S., 1997, Modelling and visualisation of a pearl quality simulator. IEEE Trans. Visual. Comput. Graph. 3, 307

Richards, C. S., 1985, A new pigmentation mutant in Biomphalaria glabrata. Malacologia 26, 145-151.

Pfaff G., Reynders P., 1999, Angle-dependent optical effects deriving from submicron structures of films and pigments. Chem. Rev. 99, 1963-1981.

Siegel S., Castellan N.J., 1988, Nonparametric statistics for the behavioral sciences. McGraw-Hill, New-York.

Snow M.R., Pring A., Self P., Losic D., Shapter J., 2004, The origin of the colour of pearls in iridescence from nano-composite structures of the nacre. Am. Mineral. 89, 1353-1358.

Talvard C., 2010, La perliculture en 2009, Points Forts de la Polynésie Française - Institut de la Statistique de la Polynésie Française $\mathrm{n}^{\circ} 8 / 2010$ pp. $1-12$.

Wada K.T., 1972, Relationship between calcium metabolism of pearl sac and pearl quality. Bull. Natl. Pearl Res. Lab. 16, 949-2027.

Webster R., Anderson B.W., 1983, Gems, their sources, descriptions and identification. Butterworths, London, pp. 505-506.

Winer B.J., Brown D.R., Michels K.M., 1991, Statistical principles in experimental design, McGraw-Hill, New-York. 